
AND JOINT SURGERY

\title{
RSA in the assessment of aseptic loosening
}

The introduction and sale of new designs of total joint prostheses have rarely been preceded by evaluation in prospective and controlled series. In some instances, early failure has caused unnecessary suffering to patients and increased costs to society. There is an obvious need for more precise tools which can evaluate new designs of implant as quickly as possible while exposing a minimum number of patients to any risk.

Aseptic loosening and wear are now the major reasons for failure, but conventional radiography can provide only relatively crude measurements of these. Routine radiographs of the hip, without special precautions, can detect movement of about $5 \mathrm{~mm}$ (Malchau et al 1995). This should be compared with implant motion of 0.15 to $0.2 \mathrm{~mm}$, which has been claimed to be the maximum compatible with bony ingrowth and stable long-term fixation. Several special radiological methods can detect smaller movement or mean changes in large series (Jones et al 1988, 1989; Braud and Freeman 1990; Hardinge et al 1991; Ilchmann et al 1992; Carlsson et al 1993; Krismer et al 1994), but some are limited to measurements of the acetabular component, can measure only in one plane, and lack adequate documentation of their precision.

Roentgen stereophotogrammetric analysis (RSA) (Selvik 1989) allows the accurate three-dimensional measurement of relative implant movement, and, in certain circumstances, measurement of wear. It is of course a research tool, requiring the planned insertion of ball markers and repeated radiography with simultaneous exposure to two tubes with implications of adequate radiographic equip-

K. G. Nilsson, MD, PhD, Consultant Orthopaedic Surgeon Department of Orthopaedics, University Hospital, S-901 85 Umeå, Sweden.

J. Kärrholm, MD, PhD, Assistant Professor

Department of Orthopaedics, Sahlgren Hospital, S-413 45 Gothenburg, Sweden.

Correspondence should be sent to Dr K. G. Nilsson.

(C)1996 British Editorial Society of Bone and Joint Surgery

0301-620X/96/11137 \$2.00

J Bone Joint Surg [Br] 1996;78-B:1-2. ment, radiation dosage and expense. The radiation dosage of a hip examination is, however, smaller than for a corresponding conventional radiograph.

The accuracy of RSA depends on several factors (Kärrholm 1989), but most series report between 0.1 and $0.8 \mathrm{~mm}$ for translation movement and $1^{\circ}$ to $2^{\circ}$ for rotation at the 99\% significance level (Kärrholm and Snorrason 1992; Nilsson and Kärrholm 1993; Önsten 1994; Thanner et al 1995). RSA has now been used for over 15 years to study both migration (implant motion over time) and inducible displacement (instantaneous implant motion caused by loading).

What have these studies taught us? Is early micromotion important? Can it be used to predict later clinical loosening?

The pattern of micromotion during the first two years after hip replacement varies considerably between different implant designs and methods of fixation. In a few cases the implant may be 'stable' over time; this means that any motion is less than the detection limit of the method. Some implants show a period of early migration with later stability; a few show more or less continuous migration.

If no micromovement can be detected in the first one to two years, then the risk of long-term loosening appears to be minimal (Kärrholm et al 1994; Ryd et al 1995a), since there would seem to be some type of bony anchorage. The complete absence of movement is rare, and it is clear that a few weeks or months of apparent early stability may be followed by an increase in the rate of migration. This may be because the area of initial bony fixation is too small to survive or because of fracture of a ceramic coating (Nilsson, Cajander and Kärrholm 1994). It may also be related to an increase in the activity of the patient.

In non-cemented porous-coated implants and revision prostheses placed on impacted cancellous allografts there is commonly an early migration of about 0.5 to $1 \mathrm{~mm}$ which is followed by stability. The early movement may be due to roughness of the bony bed or to further impaction of the graft. Migration then continues until a new equilibrium is reached. In such cases, provided that stability is reached after one year, the risk for subsequent clinical loosening 
seems to be small (Ryd et al 1995a).

Continuous migration which reaches 1 to $2 \mathrm{~mm}$ or more during the first two postoperative years is a sign of poor prognosis (Ryd et al 1995a). Comparatively high rates of migration have been reported for uncemented femoral components of press-fit design (Wykman, Selvik and Goldie 1988; Nistor et al 1991; Kärrholm and Snorrason 1993; Nistor, Lundberg and Ackerholm 1994) and types of acetabular screw ring (Snorrason and Kärrholm 1990) which are known to have high revision rates at longer follow-up (Tallroth et al 1993; Jensen, Christensen and Hørlyck 1994; Bruijn et al 1995; Malchau et al 1995; Savilahti et al 1995; Sweetnam et al 1995). The EBRA method of assessing migration has given similar results for migration of the PCA cup (Krismer et al 1994).

The interpretation of micromotion is more complicated in cemented implants because of the presence of two interfaces but it has been shown that cemented femoral components which subside more than $1 \mathrm{~mm}$ run an increased risk of clinical loosening as early as four to seven years after implantation (Kärrholm et al 1994). It has been claimed that comparatively large movement of the femoral stem inside its cement mantle is a 'normal' phenomenon of the Exeter design of hip, but motion between the cement mantle and the implant may generate abrasive wear or be a sign of radiologically invisible cement fracture. Thanner et al (1995) have shown that there was increased micromotion inside the cement mantle of Spectron prostheses with a gritblasted surface when one cement with inferior mechanical properties was compared with another.

There have been only a few retrieval studies of implants which had been followed by RSA. Most of these have shown varying amounts of migration before revision became necessary, and fibrous tissue, fibrocartilage and small areas of bony ingrowth have been found at the interface (Ryd and Linder 1989; Kärrholm, Carlsson and Snorrason 1995; Nilsson, Kärrholm and Linder 1995; Ryd et al 1995b). The migration of hydroxyapatite-coated tibial components has been associated with delamination of the coating (Nilsson et al 1994), while stable implants displayed small areas of direct bonding to bone (Nilsson, unpublished data). These few observations are, however, anecdotal compared with the large number of implants followed by RSA. Further studies are needed before we can accurately relate the recording of micromotion to the quality of the interface. The ingress of wear particles into the interface as a result of inducible displacement rather than slow migration may be important in the induction of osteolysis and late aseptic loosening.

Despite all these questions, there can be no doubt that recordings of early micromotion contain important information. The use of the method in randomised evaluation of new implant designs or methods of fixation can provide valuable data from small series of patients after a comparatively short period of observation. The findings are not yet accurately prognostic in an individual case but it is clear that there is a low risk of clinical loosening when either no micromotion is detected or it is less than $1 \mathrm{~mm}$ and stops after the first postoperative year.

K. G. NILSSON

J. KÄRRHOLM

\section{REFERENCES}

Braud P, Freeman MAR. The effect of retention of the femoral neck and of cement upon the stability of a proximal femoral prosthesis. $J$ Arthroplasty 1990;5:s5-10.

Bruijn JD, Seelen JL, Feenstra RM, Hansen BE, Bernoski FP. Failure of the Mecring screw-ring acetabular component in total hip arthroplasty: a three to seven-year follow-up study. J Bone Joint Surg [Am] 1995;77-A:760-6.

Carlsson LV, Albrektsson BEJ, Freeman MAR, et al. A new radiographic method for detection of tibial component migration in total knee arthroplasty. J Arthroplasty 1993;8:117-23.

Hardinge K, Porter ML, Jones PR, Hukins DWL, Taylor CJ. Measurement of total hip prostheses using image analysis: the MAXIMA hip technique. J Bone Joint Surg [Br] 1991;73-B:724-8.

Ilchmann T, Franzen H, Mjöberg B, Wingstrand H. Measurement accuracy in acetabular cup migration: a comparison of four radiologic methods versus roentgen stereophotogrammetric analysis. J Arthroplasty 1992;7:121-7.

Jensen HP, Christensen KS, Hørlyck E. Cementless total hip replacement with the Link Ribbed System. Acta Orthop Scand 1994;65(Suppl 256):7.

Jones PR, Taylor CJ, Hukins DWL, Hardinge K, Porter ML. Prosthetic hip failure: preliminary findings of retrospective radiograph image analysis. Eng Med 1988;17:119-25.

Jones PR, Taylor CJ, Hukins DW, Porter ML, Hardinge K. Prosthetic hip failure: retrospective radiograph image analysis of the acetabular cup. J Biomed Eng 1989;11:253-7.

Kärrholm J. Roentgen stereophotogrammetry: review of orthopedic applications. Acta Orthop Scand 1989;60:491-503.

Kärrholm J, Snorrason F. Migration of porous coated acetabular prostheses fixed with screws: roentgen stereophotogrammetric analysis. $J$ Orthop Res 1992;10:826-35.

Kärrholm J, Snorrason F. Subsidence, tip and hump micromovements of non-coated ribbed femoral prostheses. Clin Orthop 1993;287:50-60.

Kärrholm J, Borssén B, Löwenhielm G, Snorrason F. Does early micromotions of femoral stem prostheses matter? 4-7-year stereoradiographic follow-up of 84 cemented hip prostheses. $J$ Bone Joint Surg [Br] 1994;76-B:912-7.

Kärrholm J, Carlsson L, Snorrason F. Migration of porous coated press-fit acetabular cups fixed with screws. Trans Orthop Res Soc 1995;20:244.

Krismer M, Fischer M, Mayrhofer P, et al. A prospective study of the migration of two acetabular components: PCA versus RM cups. Int Orthop 1994;18:23-8.

Malchau H. On the importance of stepwise introduction of new hip implant technology. Assessment of total hip replacement using clinical evaluation, radiostereometry, digitised radiography and a national hip registry. Thesis. Gothenburg, Sweden: University of Gothenburg, 1995 .

Malchau H, Kärrholm J, Wang YX, Herberts P. Accuracy of migration analysis in hip arthroplasty: digitized and conventional radiography compared to radiostereometry in 51 patients. Acta Orthop Scand 1995: 66:418-24.

Nilsson KG, Kärrholm J. Increased varus-valgus tilting of screw-fixated knee prostheses: stereoradiographic study of uncemented versus cemented tibial components. J Arthroplasty 1993;8:529-40.

Nilsson KG, Cajander S, Kärrholm J. Early failure of hydroxyapatitecoating in total knee arthroplasty: a case report. Acta Orthop Scand 1994;65:212-4.

Nilsson KG, Kärrholm J, Linder L. Femoral component migration in total knee arthroplasty: randomized study comparing cemented and uncemented fixation of the Miller-Galante I design. J Orthop Res 1995;13:347-56.

Nistor L, Blaha JD, Kjellström U, Selvik G. In vivo measurements of relative motion between an uncemented femoral total hip component and the femur by roentgen stereophotogrammetric analysis. Clin Orthop 1991;269:220-7. 
Nistor L, Lundberg A, Ackerholm P. Rotation and subsidence of a composite femoral component analysed by roentgen stereophotogrammetry. Trans Orthop Res Soc 1994;19:245.

Önsten I. Fixation of total hip components in rheumatoid arthritis and arthrosis: a radiographic, roentgen stereophotogrammetric, densitometric and histomorphometric study. Thesis. Lund, Sweden: University of Lund, 1994.

Ryd L, Albrektsson BEJ, Carlsson L, et al. Roentgen stereophotogrammetric analysis as a predictor of mechanical loosening of knee prostheses. J Bone Joint Surg [Br] 1995a;77-B:377-83.

Ryd L, Blunn G, Hansson U, et al. The histologic difference of continuous versus initial migration. Combined Orthopaedic Research Societies Meeting, November 6-8, 1995b, San Diego, California, USA:69.

Ryd L, Linder L. On the correlation between micromotion and histology of the bone-cement interface: report of three cases of knee arthroplasty followed by roentgen stereophotogrammetric analysis. J Arthroplasty 1989;4:303-9.

Savilahti S, Myllyneva I, Lindholm TS, et al. Clinical outcome and survival of Link RS total hip prosthesis. J Bone Joint Surg [Br] 1995;77-B:369-73.
Selvik G. Roentgen stereophotogrammetry: a method for the study of the kinematics of the skeletal system. Acta Orthop Scand 1989;60 Suppl 232:1-51.

Snorrason F, Kärrholm J. Primary migration of fully-threaded acetabular prostheses: a roentgen stereophotogrammetric analysis. J Bone Joint Surg [Br] 1990;72-B:647-52.

Sweetnam DIS, Lavelle J, Muirhead Allwood W, Cohen B. Poor results of the ribbed hip system for cementless replacement. J Bone Joint Surg [Br] 1995;77-B:366-8.

Tallroth K, Slätis P, Ylinen P, Paavolainen P, Paavilainen T. Loosening of threaded acetabular components: radiographic manifestations. J Arthroplasty 1993;8:581-4.

Thanner J, Freij-Larsson C, Kärrholm J, Malchau H, Wesslén B. Evaluation of Boneloc: chemical and mechanical properties, and a randomized clinical study of 30 total hip arthroplasties. Acta Orthop Scand 1995;66:207-14.

Wykman A, Selvik G, Goldie I. Subsidence of the femoral component in the noncemented total hip: a roentgen stereophotogrammetric analysis. Acta Orthop Scand 1988;59:635-7.

\section{Orthopaedic information - a superglut?}

Two remarkable decisions were made in Hong Kong in May 1995. The first was that two established and financially viable organisations, the International Arthroscopy Association (IAA) and the International Society of the Knee (ISK), resolved to vote themselves out of existence and to form a new organisation ISAKOS (International Society of Arthroscopy, Knee Surgery and Sports Medicine). The second was that the Presidents of associations with similar interests in Europe, North America and the Western Pacific decided to establish an informal group, the aim of which was to co-ordinate the plethora of international meetings on their respective subjects. Such international conventions are expensive to organise and to attend, but they seem to increase in number every year (see pages $171-2$ of this issue). There must be a limit to the number of people who can fish the same stream; and to the load taken on by the conference-fatigued officers of each association. Their practices suffer a little more with every trip to the airport.

Do international meetings serve any useful academic purpose? Why do surgeons travel around the world to listen to papers which they have often heard before, some of which have already been published, and which are presented to very similar audiences in different lecture halls? If they wished only to hear the lectures, this could be arranged by satellite. A specialist conference, as a means of communication, is more labour-intensive, more expensive

D. J. Dandy, MD, MChir, FRCS, Consultant Orthopaedic Surgeon The Old Vicarage, Great Wilbraham, Cambridge CB1 5JF, UK.

C1996 British Editorial Society of Bone and Joint Surgery 0301-620X/96/11146 \$2.00

J Bone Joint Surg [Br] 1996;78-B:2-3 and less efficient than any journal. Often, the papers have been selected on the quality of an abstract which bears little resemblance to the final product: the creative writing of abstracts is fast becoming an art form. If a revised book of abstracts is supplied there is no need to listen to the papers.

The attraction of international meetings lies elsewhere. Where else can one meet so many colleagues from other countries, discuss old and new ideas, handle new instruments, cross cultural divides and see the great and the good bedecked in rosettes and ribbons? International meetings and journals serve very different purposes; both are important. The concept of such meetings is sound, but their number must be questioned.

National meetings, such as those of the British Orthopaedic Association, have more to offer. Surgeons in training can meet their future colleagues and learn by presenting their first major papers. Established surgeons can renew old acquaintances and specialty groups can meet separately to discuss their particular interests. National meetings help to hold the orthopaedic community together and allow it to unite on common and important issues. On a smaller scale, local or departmental meetings have an immediate relevance to clinical practice and are fundamental both to teaching and the smooth running of an orthopaedic service.

There is, of course, also a surfeit of other national meetings which an orthopaedic surgeon with a special interest may attend. More general meetings such as, in the UK, those of the British Medical Association, the Royal Colleges, and the Royal Society of Medicine deserve attention and there are many instructional courses. These meetings tend to be held in the popular periods between March and June or between September and November. The realities of clinical practice, however, are incompatible with 